\title{
O DIREITO FUNDAMENTAL SOCIAL À MORADIA E A TEORIA GERAL DO DIREITO ${ }^{1}$
}

\author{
THE FUNDAMENTAL SOCIAL RIGHT TO HOUSING \\ AND THE GENERAL THEORY OF LAW
}

\author{
JOSUÉ MASTRODI ${ }^{2}$ \\ MÁRCIA MARIA CARVALHO DA SILVA ${ }^{3}$
}

\begin{abstract}
RESUMO: A positivação constitucional do direito à moradia não garante sua aplicação na realidade social brasileira. O cenário de desabrigados bem demonstra isto. Partimos da premissa que o direito social à moradia é direito humano fundamental e, nos termos de uma abordagem realista, procuramos constatar que a falta de efetivação desse direito se dá, entre outros motivos, porque a Teoria Geral do Direito é estruturada de forma a não reconhecer como fundamental qualquer direito social, incluindo-se aqui o direito à moradia. Simplesmente, afirma-se, na Teoria do Direito, que os direitos sociais sequer são direitos subjetivos, o que impede até mesmo que ele seja tutelado pelo poder judiciário. Ainda que a Teoria Geral do Direito e a Teoria dos Direitos Fundamentais, apesar de positivamente atribuírem aos Direitos Fundamentais Sociais (e, assim, ao direito à moradia) caráter especial, esse caráter não permite que eles sejam exigíveis, com aplicabilidade imediata. Tais direitos passam a depender apenas de políticas públicas, e assim da vontade do administrador público e da disposição de recursos.

PALAVRAS-CHAVE: Teoria Geral do Direito; Teoria dos Direitos Fundamentais; Direitos Sociais; Direito à Moradia; Eficácia; Direito Objetivo versus Direito Subjetivo.

ABSTRACT: The consititutional positivation of the right to housing does not guarantee its effectiveness in Brazilian social reality. The quantity of homeless shows it clear. We take for granted that the social right to housing is both a human
\end{abstract}

Artigo recebido em 25.09.2012. Pareceres emitidos em 05.11.2012 e 10.11.2012.

Artigo aceito para publicação em 19.11.2012.

1 Trabalho de pesquisa desenvolvido no Projeto Por uma Definição Realista do Conceito de Direitos Fundamentais, vinculado à linha de pesquisa Direitos Fundamentais e Políticas de Integração Social e ao Grupo de Pesquisa Direito e Realidade Social, o que determinou os parâmetros epistemológicos e metodológicos do estudo.

${ }^{2}$ Professor de Direito da Pontifícia Universidade Católica de Campinas. Campinas, São Paulo, Brasil. Doutor em Filosofia e Teoria Geral do Direito pela Universidade de São Paulo. mastrodi@puc-campinas.edu.br

${ }^{3}$ Pesquisadora discente do Programa de Iniciação Científica da Pontifícia Universidade Católica de Campinas. Campinas, São Paulo, Brasil.marcia.m.carvalho@hotmail.com 
and fundamental right and, according to a realistic approach, we seek to verify that its lack of effectiveness is caused, among other motives, by the current structure of general theory of law, by which social rights (including the right to housing) is not acknowledged as fundamental. It is simply said, by the Theory of Law, that the social rights could not even be seen as subjective rights, preventing them from being protected by the judiciary branch. Although both General Theory of Law and Theory of Fundamental Rights give a special character to the fundamental social rights, such character does neither allow them to be required nor be immediately applied. Therefore, social rights would fully depend on public policies to be implemented, which meansthat they depend on the will of public administrator and of public budget.

KEYWORDS: Social Rights; Right to Housing; Effectiveness of Social Rights; Objective versus Subjective Rights; General Theory of Law; Theory of Fundamental Rights.

SUMÁRIO: Introdução; 1. Teoria Geral do Direito e sua Base; 2. Sobre o Desenvolvimento dos Direitos Fundamentais; 3. Teoria dos Direitos Fundamentais e o Direito à Moradia; 3.10 Direito Fundamental Social à Moradia; 4. Teoria Geral do Direito e Direito Fundamental à Moradia; 4.1 Direito Objetivo; 4.2 Direito Subjetivo; 4.3 Eficácia; Conclusão; Referências Bibliográficas.

SUMMARY: Introduction; 1. General Theory of Law and its Basis; 2. On the Development of Fundamental Rights; 3 . Theory of Fundamental Rights and the Right to Housing; 3.1 The Fundamental Social Right to Housing; 4. General Theory of Law and the Fundamental Right to Housing; 4.1 Objective Right; 4.2 Subjective Right; 4.3 Efficacy; Conclusion; References.

\section{INTRODUÇÃO}

O presente artigo tem por objetivo relacionar a Teoria Geral do Direito e a Teoria dos Direitos Fundamentais, com enfoque no direito à moradia.

Dentro de uma perspectiva realista, trataremos primeiramente de analisar a base teórica pela qual se desenvolveu a teoria geral do direito. Após, analisaremos as condições históricas pelas quais se desenvolveram os direitos fundamentais. Em seguida, abordaremos a teoria dos direitos fundamentais, com ênfase na demonstração de que o direito social à moradia é objeto dessa teoria.

Em seguida, relacionaremos os conceitos principais da Teoria Geral do Direito, em especial os de Direito Objetivo, Direito Subjetivo e Eficácia Jurídica, com o direito fundamental à moradia.

O principal problema a ser abordado é que, não obstante o direito à moradia ser um Direito Fundamental constitucionalmente assegurado, este não encontra efetividade na realidade brasileira, como bem assinalam Rolnik e Klink:

...o modelo de política habitacional calcado apenas no financiamento da compra de uma nova unidade - vigente desde os anos do BNH - não atingiu uma parcela significativa da população, entre zero e três salários mínimos de renda familiar mensal, onde se concentra mais de 90\% do déficit habitacional. (...) O Estado, por sua vez, não está estruturado para desenvolver políticas de produção de cidades ex-ante - é diminuta 
a capacidade de financiamento local da urbanização - mesmo em contextos de grande dinâmica econômica - e menor ainda a capacidade de planejamento e gestão. ${ }^{4}$

Tomamos por início deste artigo a perspectiva histórica que se segue, para compreensão do desenvolvimento da Teoria Geral do Direito.

\section{TEORIA GERAL DO DIREITO E SUA BASE}

Buscando compreender o direito para além de uma perspectiva kelseniana, impõe-se considerar o direito como algo diferente de um sistema unitário de normas perfeitamente hierarquizadas. Embora a Teoria Geral do Direito, em regra, apresente as normas como elementos dessa estrutura perfeita, pronta e acabada, isso simplesmente não corresponde à realidade. Mesmo que haja formalmente uma pirâmide normativa e um perfeito esquema de ordenação normativa, os conteúdos das normas - isto é, as expressões pelas quais as condutas humanas são prescritas - são muitas vezes contraditórios entre si, sendo improvável, senão simplesmente impossível a conformação prática desses conteúdos.

No entanto, na Europa, entre o final do século XVIII e começo do século XIX, a teoria do direito servia de doutrina descritiva dos ideais iluministas da burguesia revolucionária. Os valores liberais, apresentados como conceitos lógicos derivados de uma razão universal, serviam de pedra de toque para o estabelecimento de todo um sistema de organização social diferente daquele feudal, predominante durante toda a Idade Média. No início da Idade Moderna, essa cultura de sistematização do direito culminou na chamada Jurisprudência dos Conceitos, ${ }^{5}$ por tal teoria, as normas decorreriam logicamente daqueles conceitos previamente estabelecidos pela razão. Aliás, a substituição da Vontade Divina pela Razão Universal como fundamento da autoridade social e das normas de conduta era imprescindível para possibilitar a substituição dos costumes feudais pelas regras jurídicas.

O que levava à modificação da estrutura social eram os interesses da burguesia revolucionária, interesses estes de ordem predominantemente privada, sem preocupações com questões envolvendo Estado, soberania ou nacionalidade. A teoria geral do direito, nesse sentido, se desenvolveu num contexto de desenvolvimento de mercados e de proteção da produção industrial e do comércio. Ou seja, em sua origem, ela era uma teoria de descrição e justificação de relações sociais privadas que favoreciam os interesses mercantis. ${ }^{6}$

\footnotetext{
${ }^{4}$ ROLNIK, Raquel; KLINK, Jeroen. Crescimento Econômico e Desenvolvimento Urbano. Revista Novos Estudos. Março de 2011, p.108. Disponível em http://www.scielo.br/scielo.php?pid=S010133002011000100006\&script=sci_arttext. Acesso em 11 jul. 2012.

${ }^{5} \mathrm{Na}$ França revolucionária, a doutrina correspondente à Jurisprudência dos Conceitos era denominada Escola da Exegese. Exegese se refere à aplicação "ao pé da letra" das normas gerais e abstratas que decorriam da razão.

- A visão aqui adotada sobre a Teoria Geral do Direito a apresenta como a teoria que busca descrever a natureza do Direito, como um reflexo da manifestação das ideias gerais de uma
} 
O Estado deveria servir, no máximo, para promover a garantia da propriedade privada e do cumprimento dos contratos. Compreendido dentro do Estado, o Direito possui o papel de garantir a manutenção dos interesses da burguesia revolucionária, apresentados de forma tão geral e abstrata que, em teoria, pode-se imaginar que tais interesses não são apenas do grupo dominante, mas de toda a sociedade.

A base da Teoria Geral do Direito, sob uma perspectiva política realista, é meio para atender aos anseios da classe dominante, do capital, ${ }^{7}$ e ser fonte de expressão do poder social, e não do bem-estar ou do bem comum. Referimo-nos à luta de classes no sentido de que o Direito apenas reproduz a forma de exploração social, ${ }^{8}$ que mantém viva a forma de produção capitalista moderna. Não obstante, a teoria do direito é uma doutrina pela qual estudam-se tão somente as normas jurídicas e suas relações sintáticas dentro do ordenamento jurídico, apenas como um produto pronto e acabado, sem qualquer preocupação em identificar as causas que levaram à positivação normativa. Afirma-se que tanto o processo histórico responsável pela construção dos valores sociais predominantes, quanto o processo legislativo de positivação desses valores e interesses na forma de normas jurídicas são externos ao estudo do direito.

Assim, o fato de a Teoria Geral do Direito ter sido construída com base na preservação dos interesses próprios da burguesia revolucionária gera reflexos na realidade social contemporânea, ainda mais quando se põe a relacionar o que esta teoria define como direito objetivo ou subjetivo, como normas válidas e eficazes.

\section{SOBRE O DESENVOLVIMENTO DOS DIREITOS FUNDAMENTAIS}

Não há como precisar uma data para definir o surgimento dos Direitos Fundamentais, nem mesmo como imputar a um único acontecimento histórico como determinante deste. Durante a Idade Antiga, nenhuma referência expressiva houve no desenvolvimento dos modernos direitos humanos; ${ }^{9}$ apenas houve o desenvolvimento da ideia de direitos subjetivos, direitos naturais, a ideia de moral e ética, além de alusões pelo desenrolar das teorias filosóficas dos sofistas (que partem da natureza biológica comum dos homens,

\footnotetext{
sociedade e Estado, e em seu sentido estrito. Nesse sentido, cf. BIX, Brian. Robert Alexy, a fórmula Radbruchiana, e a Natureza da Teoria do Direito. Revista Panóptica, no 12. 2008, p. 72. Disponível em http://www.panoptica.org/marjun08pdf/marjun08007.pdf. Acesso em 01 set. 2012.

${ }^{7}$ Segundo Alyson Leandro Mascaro, a Teoria Geral do Direito é berço da "vitória de um amplo aspecto de dominação política, econômica e social de molde liberal, que vê nas instituições a salvaguarda das relações sociais e, fundamentalmente, a salvaguarda do capital." (MASCARO, Alysson Leandro. Nos extremos do Direito. Revista Lua Nova, n 57, 2002, p. 135.

${ }^{8}$ MASCARO, Alysson Leandro. Pachukanis e Stuchka: o direito, entre o poder e o capital, In NAVES, Marcio Bilharinho (org). O Discreto Charme do Direito Burguês. Campinas: Unicamp, 2009, p. 50.

${ }^{9}$ FRANCO, Alberto de Magalhães Filho. A Proto Historia dos Direitos Humanos Fundamentais. Revista Direitos Fundamentais e Democracia, vol. 7, 2010, p. 192.
} 
aproximando-se da tese de igualdade natural) e dos estoicos (que também fazem alusão à igualdade), além das formulações romanas de Cícero. ${ }^{10}$

Durante a Idade Média (séculos $\mathrm{V}$ a XV) predominou a sociedade feudal, onde os servos viviam em situação miserável, explorados pelo senhor feudal, sem qualquer noção de liberdade ou direitos, e talvez sequer com consciência da exploração. Apesar disto, o senhor "concedia ao servo uma espécie de segurança [que o servo] nunca teve. Por pior que fosse seu tratamento, o

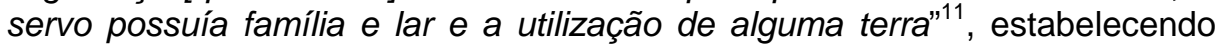
uma primitiva relação de solidariedade feudal.

No início da sociedade feudal havia uma incipiente troca de mercadorias excedentes. Essas trocas eram realizadas por mercadores, sob o controle do senhor feudal. Aliás, os senhores feudais costumavam exigir tributos de mercadores que passassem pelas estradas de seus feudos. Houve um crescimento do comércio a partir do século $\mathrm{XI}$, decorrente da expansão das capacidades produtivas, que permitiram a existência de excedentes em maior medida. Esse comércio era realizado em feiras "que negociavam mercadorias por atacado, que provinham de todos os pontos do mundo conhecido"12 de forma que, após o século XII, a economia autossuficiente dos feudos começou a sofrer transformações decorrentes de um comércio em cada vez maior expansão.

Essa expansão fortificou economicamente a classe burguesa, a ponto de esta começar a ter forças para resistir ao poder dos senhores feudais. Os comerciantes aliaram-se nas chamadas "corporações", uma forma de se organizar e se contrapor àquele poder (e assim, livrar-se dos impostos, pedágios e das demais desvantagens decorrentes da submissão). ${ }^{13}$

Com a consequente concentração de grandes fortunas mercantis nos burgos, houve aumento significativo de sua força econômica e também militar: de base econômica mercantil, estes se tornaram centroscapitalistas, onde a desigualdade social era determinada pelas diferenças patrimoniais entre as famílias. Com a possibilidade de sobrevivência fora das glebas, os servos começaram a se desvincular dos feudos para ingressar nas guildas ou trabalhar nas feiras; invenções técnicas surgiram para acelerar a produção, e institutos jurídicos foram criados para expansão dessa nova forma mercantil de organização social e econômica (como a letra de câmbio e contrato de seguro marítimo). ${ }^{14}$ Desta forma, os feudos passaram a ter diminuído seu poder econômico e social e os burgueses passaram a produzir bens com valor superior aos produtos agrícolas, a ponto de a burguesia buscar ascender socialmente, na mesma medida em que os feudos decaíam.

${ }^{10}$ CANOTILHO, José Joaquim Gomes. Direito Constitucional e Teoria da Constituição. 4. ed., Coimbra: Almedina, 2000, p. 375.

${ }^{11}$ HUBERMAN, Leo. A História da Riqueza do Homem. Rio de Janeiro: Zahar, 1981, p. 14.

${ }^{12}$ HUBERMAN, Leo. A História da Riqueza do Homem. Op. cit., p. 32.

${ }^{13}$ HUBERMAN, Leo. A História da Riqueza do Homem. Op. cit., p. 36-37.

${ }^{14}$ COMPARATO, Fábio Konder. A Afirmação Histórica dos Direitos Humanos. 7. ed., São Paulo: Saraiva, 2010, p. 59. 
Nesta perspectiva, ocorreu a Revolução Francesa (marco pela qual se estipulou considerar o início da Idade Moderna), uma forma violenta de conflito que resultou na vitória do ideal burguês e a partir da qual se passaram a positivar juridicamente certos direitos que o novo grupo social dominante reputava naturais. Foram estabelecidas declarações de caráter moral sobre os direitos humanos, baseadas nos ideais de liberdade, igualdade e fraternidade (que, mais tarde, são tomados na teoria dos direitos fundamentais como base dos direitos de primeira, segunda e terceira dimensão). Porém, de um ponto de vista realista, parece-nos que o fundamento da Revolução não era especificamente declarar direitos. Afinal, os direitos declarados eram apenas formais, de caráter abstrato e até ilusório, já que não era possível, na prática, que tais direitos fossem efetivados para todos os membros da sociedade. ${ }^{15}$

O ideário liberdade está intimamente ligado à liberdade econômica necessária para garantir a realização das transições comerciais e garantir a propriedade privada, de forma que foi o primeiro e principal direito desenvolvido (primeira geração), em especial por sintetizar os principais interesses do grupo social que ascendeu ao poder político após a Revolução, e que acabou servindo de base, de fator determinante para o desenvolvimento da Teoria Geral do Direito. As relações sociais passam a ser regidas pela lógica burguesa, pela qual os valores mais prestigiados são a felicidade individual, a propriedade privada e a acumulação de capital. Como afirmado linhas atrás, não era possível garantir de fato direitos de propriedade e sucesso individual a todo mundo ao mesmo tempo. O motivo é simples: os recursos materiais são escassos e a propriedade desses bens acaba por determinar o sucesso de uns em detrimento de outros, estes últimos sem condição material de obter esses bens simplesmente porque eles já pertencem aos primeiros. A liberdade de obter bens é dada a todos, como se fosse possível a todos terem sucesso nessa empreitada. Por sua vez, o ideário igualdade estaria relacionado à liberdade política, no sentido que deveriam ter os mesmos direitos (ou tratados nas mesmas condições que os membros dos antigos primeiro e segundo estamentos, nobreza e clero). Tanto que a igualdade que se desenvolveu foi a denominada isonomia, ou igualdade formal de todos perante a lei (as mesmas normas devem ser igualmente aplicadas a todas as pessoas). O ideário fraternidade tinha relação com a necessidade de agregação social, mas não nos parece que, ao menos até o século $X X$, ele tenha servido de base para promover a organização da sociedade de fato.

Aliás, foi em meados do século $X X$ que se passou a identificar as espécies de direitos humanos segundo sua conformação a cada um dos 3 elementos do tríptico revolucionário: os primeiros direitos humanos afirmados

\footnotetext{
${ }^{15}$ Segundo Wolkmer, a declaração Francesa refere-se na verdade a "direitos formais da sociedade burguesa," isto é, a critérios necessários para a organização da nova ordem econômica liberal. WOLKMER, Antonio Carlos. Marx, a questão Judaica e os Direitos Humanos. Revista Sequência, $n^{\circ} 48$, jul. 2004, p. 21.
} 
(e posteriormente positivados como fundamentais) e, por esse motivo, chamados de direitos de primeira dimensão, foram justamente os direitos liberais conquistados pelas revoluções burguesas do século XVIII. Os direitos fundamentais de primeira dimensão referem-se à positivação dos direitos do homem e do cidadão (ou melhor, direitos humanos) afirmados em decorrência do pensamento liberal burguês e individualista, pelo qual todo homem seria autônomo em suas decisões e as autoridades públicas não deveriam intervir na esfera das relações privadas. ${ }^{16}$ Tais direitos imporiam ao Estado o dever de se abster de se imiscuir em certos âmbitos da esfera individual.

Os direitos de segunda dimensão, fundados na igualdade (material e não apenas formal); foram afirmados apenas no século XIX e positivados com mais ênfase no século seguinte, e decorreram de demandas de grupos sociais insatisfeitos com a estrutura econômica vigente, inteiramente erigida sobre o ideário da liberdade. Tanto é que, para que tais direitos pudessem ser concretizados, o Estado e a sociedade precisariam ser reorganizados para permitir que recursos públicos fossem direcionados à promoção dos direitos relacionados à igualdade material - algo totalmente contraditório à ideia liberal de um Estado que não deve se meter nos assuntos privados em hipótese alguma. Já os direitos de terceira dimensão, relacionados à fraternidade, são apresentados como direitos de solidariedade social e até se vinculam a questões universais (acima das questões envolvendo lutas sociais, pois em tese todos os grupos sociais seriam igualmente interessados nesses direitos, como por exemplo, o direito ao meio ambiente). ${ }^{17}$

A estrutura do Estado moderno e da organização das relações sociais após 1.789, porém, tem-se mantido mais ou menos a mesma desde então. Ainda que nos séculos seguintes tenha havido, como houve, luta por novos direitos, a forma como o Estado e a sociedade se organizam ainda tem base muito sólida na forma mais adequada à dinamização das trocas econômicas e, por conseguinte, nos direitos de primeira dimensão, necessários para permitir essa dinamização. No desenho histórico apresentado, fica claro que, quando começaram a surgir demandas por novas formas de estrutura social e por novos direitos, já havia uma estrutura social montada segundo interesses liberais e direitos de primeira dimensão.

Por mais que se reformasse o Estado ou se modificasse politicamente a sociedade para dar lugar aos direitos de segunda ou de terceira dimensão, Estado e sociedade já estavam construídos e consolidados num determinado

\footnotetext{
${ }^{16}$ SARLET, Ingo Wolfgang. A Eficácia dos Direitos Fundamentais. 10. ed., Porto Alegre: Livraria do Advogado, 2009, p. 46.

${ }^{17} \mathrm{Em}$ que pese o fato de os direitos de terceira dimensão serem apresentados segundo estatuto próprio e serem considerados os chamados direitos difusos sob esse gênero, há quem considere que esses direitos, na verdade, se submetem ora ao gênero dos direitos liberais, ora ao dos direitos sociais. Cf. MASTRODI, Josué. Direitos Sociais Fundamentais. Rio de Janeiro: Lumen Juris, 2008, passim.
} 
sentido, segundo determinados interesses, ${ }^{18}$ que, em termos concretos, não seriam pura e simplesmente substituídos pelos novos (a não ser que, a exemplo do que aconteceu com os nobres do antigo regime, os liberais perdessem seu predomínio socioeconômico e não mais tivessem condições de lutar por sua visão de mundo para a manutenção das estruturas sociais). A própria teoria geral do direito se estruturou nesse sentido, isto é, adequada aos direitos de primeira dimensão, a ponto de não conseguir reconhecer os direitos de segunda e terceira dimensão na mesma medida que reconhece os de primeira.

As primeiras ideias ligadas aos direitos fundamentais sociais deram-se na esfera trabalhista, gerada pelo grande número de acidentes de trabalho (o que trazia prejuízos para o capital) e o consequente desenvolvimento de sindicatos. Este processo tardio de desenvolvimento dos direitos sociais trouxe consequências até os dias de hoje, como a falta de eficácia de alguns destes, e a construção de uma Teoria Geral do Direito de base eminentemente privada, dado que no final do século XVIII o Estado não se prestava a garantir os direitos de segunda dimensão.

\section{TEORIA DOS DIREITOS FUNDAMENTAIS E O DIREITO À MORADIA}

É necessário definir o objeto do presente estudo; para tal, porém, trataremos de nos afastar, o máximo possível, do uso de "conceitos" enrijecidos, recorrentes e usuais "aproximando-se à força de uma história individualista, subjetivista, intencionalista das construções intelectuais." ${ }^{19}$

Diversos são os autores que desenvolvem o tema dos Direitos Fundamentais. Por exemplo, segundo Cristina M. M. de Queiroz, "não se pode falar de uma teoria dos direitos fundamentais, mas sim numa multiplicidade ou diversidade de teorias dos direitos fundamentais." ${ }^{20}$ Diante disto, a autora considera que os Direitos fundamentais:

...apresentam-se, genericamente, como limite ao poder do Estado, e ainda como fim da própria atividade público-estadual (política dos direitos fundamentais).

\footnotetext{
18 Segundo Wolkmer, os direitos humanos, apresentados como uma bandeira de liberdade, servem em termos concretos para o benefício do interesse de um grupo social específico e não da sociedade como um todo, e se desenvolvem para "o ser particular que pertence a uma classe a burguesia." WOLKMER, Antonio Carlos. Marx, a questão judaica e os direitos humanos. Revista Sequência, no 48, jul. 2004, p. 23-25.

${ }^{19}$ HESPANHA, Antônio Manuel. Categorias: Uma reflexão sobre a prática de classificar. Revista Análise Social. Vol. XXXVIII. 2003, p. 823. Disponível em http://analisesocial.ics.ul.pt/documentos/ 1218791402J5rXO3fg3Hg98TM7.pdf. Acesso em 17 jul. 2012.

${ }^{20}$ Segundo a autora, dentre as teorias existentes estão a "da ordem de valores" (os direitos fundamentais são ordem de valores previstos na Constituição; a "teoria social" (considera os Direitos fundamentais como possuídos de uma tripla dimensão: individual, institucional e social); "teoria democrático-funcional" e "teoria socialista (confere aos Direitos fundamentais funcionalização extrema). QUEIROZ, Cristina M. M. Direitos Fundamentais: Teoria Geral, Editora Coimbra 2002, p. 77.
} 
A dignidade da pessoa humana como "princípio constitucional supremo" apresenta-se como "fundamento" da sociedade político-estadual, isto é, como "norma fundamental" e como direito fundamental. ${ }^{21}$

Segundo o autor George Marmelstein Lima:

Direitos fundamentais são normas jurídicas, intimamente ligadas à ideia de dignidade da pessoa humana e de limitação do poder, positivadas no plano constitucional de determinado Estado democrático de direito fundamentam e legitimam todo ordenamento jurídico. ${ }^{22}$

É indiscutível, entre as principais teorias (saliente-se, as teorias nem sempre condizem com a realidade social) sobre Direitos Fundamentais, que estes são os valores-base do ordenamento jurídico, provocando "mudança significativa no Direito Positivo", de forma que "o ordenamento jurídico é interpretado hoje, segundo a moderna hermenêutica constitucional, a partir dos direitos fundamentais e segundo o sentido imposto por estes.. ${ }^{23}$ Desta forma, estão positivados constitucionalmente e objetivam oralimitar a ação do Estado (como nos direitos de primeira dimensão), ora a impor-lhe uma prestação positiva (como nos direitos sociais), buscando alcançar a tão almejada "dignidade da pessoa humana."

Porém,ressalte-se que, embora almejada no plano teórico dos direitos fundamentais, a dignidade da pessoa humana não se mostra possível na prática, especialmente para aquela imensa maioria que não pertence à classe social mais alta. Essa perspectiva idealista, segundo a qual os homens, detentores desta dignidade, teriam a possibilidade de exercer todos os seus direitos fundamentais, não refletena realidade social, pois não encontramos "nenhuma das qualidades daquele Homem universal das declarações de Direitos" ao mesmo tempo em que vemos "um sistema jurídico incapaz de prover direitos a todos eles." ${ }^{24}$ A perspectiva histórica do desenvolvimento tanto dos Direitos Fundamentais quanto da base da Teoria Geral do Direito nos mostra o motivo pelo qual o sistema jurídico é incapaz de ser fonte ou proteção da dignidade humana de forma concreta.

A estrutura econômica (aqui entendida como as condições de produção e, consequentemente, sobrevivência dos membros da sociedade) é o fator determinante para estabelecer o sistema social, de forma que o que realmente fundamenta (entenda-se, origina) os direitos fundamentais são as relações políticas e econômicas formadas historicamente na sociedade, e não um

${ }^{21}$ J. ISENSEE, apud QUEIROZ, Cristina M. M. Direitos Fundamentais: Teoria Geral. 1. ed., Coimbra: Editora Coimbra, 2002, p. 221.

${ }^{22}$ LIMA, George Marmelstein. Curso de Direitos Fundamentais. São Paulo: Editora Atlas, p. 20.

${ }^{23}$ MASTRODI, Josué. Sobre o Real Fundamento dos Direitos Fundamentais. Revista Digital de Direito Público, vol. 1, nº 1, 2012, p. 150-187.

${ }^{24}$ MASTRODI, Josué. Sobre o Real Fundamento dos Direitos Fundamentais. Revista Digital de Direito Público, vol. 1, nº 1, 2012, p. 181. 
etéreo princípio da dignidade humana; os direitos fundamentais são meio pelo qual se pode lutar para a redução das desigualdades, ${ }^{25}$ e aí sim promover concretamente a dignidade das pessoas de carne e osso. Aliás, se levado em conta o princípio democrático, pelo qual todo poder emana do povo e em seu nome deve ser exercido (Constituição Federal, artigo $1^{\circ}$, parágrafo único), os interesses da maioria dos cidadãos determinariam todas as ações do Estado e, nesse sentido, os direitos sociais seriam levados em muito mais conta que os direitos individuais, dado seu caráter de proteção àquela maioria que não tem acesso real aos direitos formais de primeira dimensão,

Só que o "Estado" tem um pecado original: não é um Estado democrático e é mais permeável à influência dos grandes interesses privados do que o Estado democrático, pela simples, mas decisiva, razão de que as entidades em que assenta esse tal Estado ...não prestam contas a ninguém nem respondem politicamente pela sua ação. ${ }^{26}$

O instrumento para a possível luta está posto através da positivação dos direitos fundamentais. ${ }^{27}$ Nossa Constituição Federal de 1988 "permitiu um avanço extraordinário na teoria jurídica dos direitos fundamentais,", ${ }^{28}$ de forma que foram considerados como cláusula pétrea, conforme artigo 60 , $\S 4^{\circ}$, IV da CF (não podem ser abolidos do ordenamento, e alterados apenas para aumentar sua amplitude); além de, teoricamente, possuírem aplicação direta e imediata (artigo $5^{\circ}$, § $1^{\circ}$ da CF).

Não obstante haver divergências doutrinárias sobre a existência ou não de dimensões de direitos fundamentais, consideramos que, de forma interativa e não linear, os direitos fundamentais podem ser classificados em dimensões, conforme apresentadas no item anterior deste artigo. A propósito dos direitos de segunda dimensão (ou geração), LIMA discorre que:

Nesta acepção, os direitos fundamentais de segunda geração funcionam como uma alavanca ou uma catapulta capaz de proporcionar 0 desenvolvimento do ser humano, fornecendo-lhe as condições básicas para gozar, de forma efetiva, a tão necessária liberdade. ${ }^{29}$

São assim, direitos positivos, no sentido de exigirem que o Estado aja para garantir sua efetivação, assegurando aos necessitados trabalho,

\footnotetext{
${ }^{25}$ MASTRODI, Josué. Sobre o Real Fundamento dos Direitos Fundamentais. Revista Digital de Direito Público, vol. 1, $\mathrm{n}^{\circ}$ 1, 2012, p. 183-184.

${ }^{26}$ NUNES, António José Avelãs. As Duas Últimas Máscaras do Estado Capitalista. Revista Pensar. Vol. 16, n² 2, Fortaleza, 2011, p. 417.

${ }^{27}$ Salienta-se que a diferença existente entre os Direitos Fundamentais e Direitos Humanos encontra-se no seu âmbito de positivação, sendo o primeiro no âmbito nacional, e o segundo internacional.

${ }^{28}$ LIMA, George Marmelstein. Efetivação do Direito fundamental a Saúde pelo Poder Judiciário. Monografia de final de curso. Faculdade de Direito da Universidade de Brasília: Brasília, 2003, p. 19.

${ }^{29}$ LIMA, George Marmelstein. Curso de Direitos Fundamentais. São Paulo: Editora Atlas, 2009, p. 20.
} 
educação, saúde, lazer, habitação (ao contrário dos direitos de primeira dimensão, reputados negativos por se afirmar que eles se efetivam por meio de abstenção estatal).

\subsection{O Direito Fundamental Social à Moradia}

Os direitos sociais estão previstos no artigo $6^{\circ}$ da Constituição Federal, que demandam uma prestação positiva do Estado e têm como objetivo a defesa dos necessitados, a busca pela igualdade social e erradicação da pobreza. São direitos humanos de segunda dimensão e, por sua positivação constitucional, devem ser considerados igualmente como direitos fundamentais.

Os direitos sociais devem ser entendidos como a materialização, no plano concreto, das Liberdades Públicas existentes no plano metafísico da matriz liberal. Os direitos sociais nada são senão as Liberdades Públicas em sua dimensão positiva. Não podemos imaginar direitos mais fundamentais que estes. ${ }^{30}$

Dentre os direitos sociais, é constitucionalmente previsto o direito à moradia. Pela positivação deste direito, deve-se garantir o atendimento a um aspecto importantíssimo da dignidade humana (que é base ideal dos direitos fundamentais, como já explicitado). No entanto, a realidade social nos mostra que não há qualquer respeito à dignidade dos desabrigados.

O direito à moradia a que se refere é em sentido amplo, pois está compreendido além do direito de ter um lar, um abrigo, um teto. Tal direito, para que seja efetivo, é necessário que venha acompanhado de outros requisitos. $\mathrm{O}$ direito à moradia, por ele mesmo, conforme previsto no artigo $6^{\circ}$ de nossa Constituição Federal, garante ao indivíduo que ele tenha um local físico (uma construção) de acordo com todas as regras de segurança necessárias para um prédio, ou seja, uma estrutura que garanta que o morador ficará livre de acontecimentos que ponham em risco sua integridade física ou sua vida. Além da segurança à moradia, é garantida a proteção ao relento, um tamanho adequado do local para evitar insalubridade e a miséria. Este direito também assegura que o morador tenha a posse tranquila $\mathrm{e}$ pacífica de seu bem. A moradia deve também estar localizada em um local seguro, onde seja possível o morador entrar e sair de sua casa sem perigo, sem prejuízo a seus bens materiais ou a sua vida. É essencial que seja perto de seu trabalho ou de fácil acesso. O local, ainda, tem que ser acessível a serviços públicos, como água tratada, esgoto, iluminação pública, energia elétrica e qualquer outra infraestrutura que o Estado disponibiliza nas cidades. ${ }^{31}$

\footnotetext{
${ }^{30}$ MASTRODI, Josué. Direitos Sociais Fundamentais. Op. cit., p. 82. "Assim, por serem os direitos sociais base da convivência em sociedade e pressuposto para o exercício das liberdades públicas, os direitos sociais são direitos fundamentais." MASTRODI, Josué. Direitos Sociais Fundamentais. Op. cit., p. 112.

${ }^{31}$ Todas essas considerações, em que pesem o fato de se dever considerá-las óbvias, também fazem parte de inúmeros tratados internacionais, em especial as Convenções Internacionais Habitat I e II.
} 
Desta forma, considera-se que o direito àmoradia é direito fundamental social garantido em sentido amplo pelo ordenamento jurídico, inclusive com base constitucional. Porém na vida real não é isso que se encontra. Tendo estas considerações de ordem histórica como base, passaremos a relacionar a objetividade, subjetividade, eficácia e validade destes direitos na realidade social brasileira.

\section{TEORIA GERAL DO DIREITO E DIREITO FUNDAMENTAL À MORADIA}

\subsection{Direito Objetivo}

Diversas são as teorias que buscam definir o que compreende o direito objetivo. Uma perspectiva idealista dos direitos fundamentais é aquela segundo a qual a simples positivação de um direito dentro do ordenamento já Ihe confere caráter objetivo. Segundo esta posição:

A dimensão objetiva consagra-se o reconhecimento de que os Direitos Fundamentais expressam os valores mais relevantes de determinada comunidade política, e que o zelo e defesa desses direitos não é mais exclusivamente uma função do Estado, mas desta comunidade. ${ }^{32}$

Porém, no presente ensaio busca-se adotar a perspectiva realista, segundo a qual existe um Direito não apenas quando uma norma em vigor (válida juridicamente) o garante, mas sim quando a conduta fática na realidade social o exprime. Como bem demonstra Alf Ross, a ciência jurídica visa a conhecer a efetiva conduta humana ${ }^{33}$, e não apenas o prescrito pela norma.."34

Desta forma, segundo tal perspectiva realista, para que o Direito à moradia seja um direito objetivo, não basta a sua positivação no ordenamento jurídico. É também necessário ele seja aplicado na prática, que produza efeitos, que vincule o poder público. Ou seja, que as pessoas tenham de fato moradia (em sentido amplo), e não apenas que tenham o direito a um dia, quem sabe, poderem morar em algum lugar.

Apesar de o direito à moradia ser um direito fundamental social, expressamente garantido no artigo $6^{\circ}$ da Constituição Federal, e que assim deveria direta e imediatamente vincular os poderes públicos (e também os particulares ${ }^{35}$ ), o direito à moradia não encontra na realidade social aplicação

\footnotetext{
${ }^{32}$ MAILLART, Adriana da Silva; SANCHES, Samyra Dal Farra Naspolini. Os Limites à Liberdade na Autonomia Privada. Revista Pensar, vol. 16. Fortaleza, 2011, p. 28. Disponível em http://ojs.unifor.br/index.php/rpen/article/view/2144. Acesso em 23 jul. 2012.

${ }^{33}$ KELSEN, Hans. Teoria Pura do Direito. 6. ed., São Paulo: Martins Fontes, 2003, p. 421.

${ }^{34}$ Sobre a perspectiva realista de Alf Ross, cf. KELSEN, Hans. Teoria Pura do Direito. Op. cit., p. 423 (nota de rodapé 9 em que Kelsen apresenta a perspectiva realista em contraposição à idealista).

${ }^{35}$ Quanto a necessária limitação da autonomia privada pelos direitos fundamentais importantes considerações no artigo Os limites à liberdade na autonomia privada, de Adriana da Silva Maillart e Samyra Dal Farra Naspolini Sanches. MAILLART, Adriana da Silva; SANCHES, Samyra Dal Farra Naspolini. Os Limites à Liberdade na Autonomia Privada. Revista Pensar, vol. 16. Fortaleza, 2011, p. 9-30. Disponível em http://ojs.unifor.br/index.php/rpen/article/view/2144. Acesso em 23 jul. 2012.
} 
(eficácia), tendo em vista o número imenso de desabrigados, bem como o número de quem sofre pela falta de possibilidade de este direito ser tutelado pelo poder judiciário. Essa falta de aplicação e de proteção judicial é consequência, sem dúvida, de o direito à moradia não ser reconhecido como direito pela Teoria Geral do Direito.

A Teoria Geral do Direito desenvolveu-se, conforme perspectiva histórica apontada, para descrever e organizar sistematicamente os interesses das pessoas singularmente consideradas segundo princípios de natureza exclusivamente liberal. Como sistemas possuem uma lógica interna dependente de adequação, a ponto de sua estrutura negar a existência de lacunas (ausência normativa) e de antinomias (conflito entre normas), a estrutura original da Teoria Geral do Direito, baseada em direitos de primeira dimensão, simplesmente não reconhece direitos de segunda ou de terceira dimensões, já que estes são contraditórios ao sentido de sua própria estrutura. É como se os direitos sociais, mesmo existindo, não pudessem ser conhecidos no âmbito dessa teoria, por serem estranhos à sua ordem interna.

\subsection{Direito Subjetivo}

A divergência doutrinária sobre a existência ou não de direitos subjetivos repousa na distinção entre direitos que antecedem o direito positivo e que devem ser reconhecidos por este, dada sua importância ou evidência (a teoria dos direitos naturais foi utilizada como bandeira da burguesia revolucionária para que as autoridades reconhecessem direitos de liberdade e igualdade), e direitos que somente podem ser considerados existentes após serem constituídos por um ordenamento jurídico, no sentido de que não há direitos anteriores à ordem jurídica. Nesta segunda perspectiva, não há direitos subjetivos anteriores ou externos ao Estado e que este deve reconhecê-los; direitos subjetivos são exclusivamente aqueles que são definidos como tais pelo direito objetivo (entendido como o direito composto pelo ordenamento jurídico positivo). Ou seja, os sujeitos só possuem direitos (direitos subjetivos) na medida e na extensão prescrita pelo ordenamento jurídico. ${ }^{36}$ Assim, o direito subjetivo existe quando o seu titular tem o poder de demandar judicialmente "os poderes, as liberdades ou mesmo o direito à ação ou às ações negativas ou positivas que Ihe foram outorgadas pela norma consagradora do direito fundamental em questão"37.

Os direitos sociais em geral, e em especial, neste estudo, o direito à moradia, percebe-se claramente que, apesar de ele ser constitucionalmente declarado, na realidade não é passível de ser demandados judicialmente. $\mathrm{O}$ direito à moradia é entendido muito mais como um direito subjetivo na primeira acepção indicada acima, sem aptidão para ser judicialmente exigido.

\footnotetext{
${ }^{36}$ Como bem demonstra KELSEN, Hans. Teoria Pura do Direito, Op. cit., p. 140-155.

${ }^{37}$ SARLET, Ingo Wolfgang. A Eficácia dos Direitos Fundamentais: uma teoria geral dos direitos fundamentais na perspectiva constitucional. 10. ed., rev. atual. e ampl. Porto Alegre: Editora Livraria do Advogado, 2009, p. 154.
} 
A Teoria Geral do Direito não se desenvolveu a ponto de compreender direitos sociais como direitos subjetivos (na segunda acepção, como direitos exigíveis). Como consequência, ao contrário dos direitos de primeira dimensão, que são reconhecidos como direitos subjetivos claramente exigíveis pela Teoria Geral do Direito, o direito social à moradia necessita da promulgação de leis e regulamentos específicos para que ele se realize. Para que o direito à moradia seja provido é necessário que do Estado realize prestações positiva, que se dá por meio de políticas públicas, que são "ações que determinam o padrão de proteção social implementado pelo Estado, voltadas, em princípio, para a redistribuição dos benefícios sociais visando a diminuição das desigualdades estruturais produzidas pelo desenvolvimento socioeconômico". ${ }^{38}$

No caso do direito à moradia, a ação estatal necessária é aquela voltada para prover a moradia em sentido amplo que, buscando diminuir as desigualdades sociais, fornece habitação adequada por meio de políticas públicas sociais, o que é inviável na realidade social, considerando a limitação dos recursos públicos e a falta de interesse político na ampliação desses recursos para a concretização deste direito fundamental.

Em suma, o direito à moradianão é exigível por não ser compreendido como direito subjetivo. A previsão constitucional do artigo $6^{\circ}$ da Constituição Federal não garante o poder de ser requerido judicialmente.

\subsection{Eficácia}

Segundo a Teoria Geral do Direito, eficácia, em sentido amplo, é o poder que uma norma possui para produzir seus efeitos e ser aplicada pelos seus destinatários ${ }^{39}$, como bem explicita Norberto Bobbio: "O problema da eficácia de uma norma é problema de ser ou não seguida pelas pessoas a quem é dirigida (os chamados destinatários da norma jurídica) e, no caso de violação, ser imposta através de meios coercitivos pela autoridade que a evocou". ${ }^{40}$

Dentro da perspectiva idealista, eficácia pode ser dividida em 2 parâmetros distintos: a eficácia jurídica e a eficácia social (ou efetividade). ${ }^{41}$ A eficácia jurídica estaria ligada ao plano do "dever ser" preconizado pela norma constitucional. Possui eficácia jurídica aquela norma que está apta a produzir efeitos jurídicos e possui meios para ser aplicada no caso concreto, ou seja,

\footnotetext{
${ }^{38}$ HÖFLING, Eloisa de Mattos. O Estado e Políticas (públicas) Sociais. Cadernos Cedes, ano XXI, n० 55, nov. 2001, p. 31.

39 DIAS, Francisco Barros. O Significado das Expressões Eficácia e Efeito entre alguns Doutrinadores na Teoria Geral do Direito e no Campo Processual. Revista FIDES, vol. 1, $\mathrm{n}^{\circ} 1$ : Natal, 2010, p. 18. Disponível em http://dialnet.unirioja.es/servlet/articulo?codigo=3646732. Acesso em 13 jun. 2012.

${ }^{40}$ BOOBIO, Norberto. Teoria da Norma Jurídica. Trad. Fernando Pavan Batista e Ariane Bueno Sudatti. Bauru: Edipro, 2008, p. 47.

${ }^{41}$ Dentre os principais autores sobre o tema encontram-se José Afonso da Silva, Virgílio Afonso da Silva e Ingo Wolfgang Sarlet; não obstante as divergências em determinados pontos, os referidos autores convergem na assertiva da divisão da eficácia em social e jurídica. Cf. SARLET, Ingo Wolfgang. A Eficácia dos Direitos Fundamentais: uma teoria geral dos direitos fundamentais na perspectiva constitucional. Op. cit., p. 236 e ss.
} 
esta "eficácia diz a respeito da aplicabilidade, exigibilidade ou executoriedade da norma, como possibilidade de sua aplicação jurídica". ${ }^{42} \mathrm{O}$ fato de o direito à moradia ser um direito fundamental social (art. $6^{\circ}$ da Constituição Federal), e considerando a importância conferida pelo constituinte brasileiro para tal direito (como já explicitado), pode-se perfeitamente considerar que ele possui eficácia jurídica. Porém, sob a ótica realista, o que define a eficácia de uma norma é a sua aplicação na realidade social, o que passamos a analisar.

Compreende esta na produção de efeitos determinados pela lei, no seio da sociedade, ou seja, no plano dos fatos. Está relacionada com a efetividade do direito em análise, compreendendo assim a aplicação propriamente dita do direito à moradia. No caso do Direito fundamental à moradia, entendemos que ele não é eficaz na realidade brasileira.

O principal meio de se alcançar a eficácia social do direito à moradia, por ser direito de dimensão positiva, seria através das políticas públicas. Interessa-nos, portanto, a análise da realidade de desabrigados no Brasil, que comprova a ineficácia social do direito à moradia, em especial pela eloquente ausência dessas políticas públicas. Assim demonstra o relatório elaborado pelo Ministério das Cidades que, confirmando a falta de eficácia social nas políticas relacionadas ao direito à moradia, mostra que no Brasil há déficit de 7,2 milhões de habitações. ${ }^{43} \mathrm{O}$ que nos faz considerar que o direito à moradia não é integral e nem prioritariamente protegido pelas políticas públicas. Assim, Josué Mastrodi bem explicita:

O Estado é um dos mais poderosos instrumentos a serviço das pessoas. No entanto, essa ordem na escala de valores (de matriz liberal, que precisa ser alterada para outra matriz social), em que eficiência econômica prevalece ante a proteção dos direitos fundamentais, faz com que todo sistema estatal funcione mais em prol dos mercados que em favor da dignidade humana [aqui representada pelo direito à moradia]. ${ }^{44}$

Desta forma, "a efetivação [sinônimo de eficácia social] de direitos humanos e sociais, em muitos países latino americanos, é marcada pela distância entre o real e o texto legal," ${ }^{45}$ não sendo diferente no que concerne ao direito fundamental à moradia no Brasil.

Atingir a eficácia social do direito à moradia seria possível também por decisões proferidas pelo poder judiciário que condenassem o Estado a obrigações de fazer, para o fim de que se efetive o direito à moradia.

\footnotetext{
${ }^{42}$ SARLET, Ingo Wolfgang. A Eficácia dos Direitos Fundamentais: uma teoria geral dos direitos fundamentais na perspectiva constitucional. Op. cit., p. 237.

${ }^{43}$ BRASIL. Governo Federal. Ministério das Cidades. Caderno M Cidades no 4 - Habitação Política Nacional de Habitação. Novembro de 2004. Disponível em: http://www.cidades.gov.br/ images/stories/ArquivosSNH/ArquivosPDF/4PoliticaNacionalHabitacao.pdf. Acesso em 20 jul. 2012.

${ }^{44}$ MASTRODI, Josué. Direitos Sociais Fundamentais. Rio de Janeiro: Lumen Juris, 2008, p. 99.

45 SPOSATI, Aldaiza. Tendências Latino-americanas da Políticas Social Pública do Século 21. Revista Katálysis, Florianópolis, v. 14, nº 1, jan./jun. 2011, p. 105.
} 
Mas, como já demonstrado, não é possível, pois a estrutura de compreensão da Teoria Geral do Direito não admite que direitos fundamentais sociais sejam entendidos como direitos subjetivos. Como demonstração da inexistência de eficácia do Direito a moradia,

o relatório de monitoramento do direito à moradia no Brasil, endereçado à ONU em 2004, chega a sugerir que nossos tribunais não enxergam os grupos vulneráveis (notadamente, a parte das classes mais pobres obrigada a produzir sua moradia na informalidade) como titulares do direito à moradia ${ }^{46}$.

Ademais, mesmo que o judiciário emitisse uma ordem mandamental para que executivo promovesse a moradia, esta dificilmente seria cumprida, já que os recursos financeiros deste são limitados, e o cumprimento da ordem dependeria da possibilidade de recursos disponíveis. Resta-nos clara a falta de eficácia (efetividade) do direito fundamental à moradia, que fica condicionado à vontade dos agentes políticos em destinar verbas públicas para a realização de políticas públicas sociais.

\section{CONCLUSÃO}

O desenvolvimento histórico da Teoria Geral do Direito nos mostra que ela não foi estruturada para prover os direitos fundamentais sociais, em especial o direito à moradia, pois desde sua origem serviu para organizar direitos relacionados à satisfação de interesses ligados à classe empresária. Assim, considerando que o desenvolvimento in abstrato dos Direitos Fundamentais tende a conferir direitos concretos aos burgueses, conclui-se pela ausência do direito fundamental social à moradia na realidade social, pois jamais foi identificado de fato como um direito subjetivo socialmente eficaz.

O direito à moradia (artigo $6^{\circ}$ da Constituição Federal) é um direito fundamental social de segunda dimensão que, apesar de ser garantido constitucionalmente, não se encontra aplicado na realidade social. Para sua implementação se faz necessário prestações positivas do Estado, por meio de políticas públicas. Porém, estas estão condicionadas à previsão no orçamento público e dependem da criação de lei que as autorize. Ainda, as políticas públicas existentes para prover tal direito mais parecem exceção do que regra, e não significam que o direito à moradia esteja sendo cumprido, dada a insignificância da extensão dessas políticas diante do déficit de moradias. Tal quadro mostra a falta de eficácia do direito à moradia, que sequer é reconhecido como direito judicialmente exigível, deixando claro que há grande distância entre o real e o texto legal. ${ }^{47}$

\footnotetext{
${ }^{46}$ ABREU, João Maurício Martins de. A Moradia Informal no Banco dos Réus: discurso normativo e prática judicial. Revista de Direito FGV n 14, São Paulo, 2011, p. 410.

47 SPOSATI, Aldaiza. Tendências Latino-americanas da Política Social Pública no Século 21. Revista Katál. Vol. 14, no 1: Curitiba, 2011, p. 105. Disponível em http://www.scielo.br/scielo.php? pid=S1414-49802011000100012\&script=sci_arttext. Acesso em 03 set. 2012.
} 
A insuficiência das políticas públicas é demonstrada pelo fato de faltarem cerca de 7,2 milhões de moradias no Brasil, e isso segundo números oficiais do próprio governo federal. Outro exemplo está na implementação do Programa Minha Casa Minha Vida ${ }^{48}$ no município de Campinas onde, de acordo com o informativo apresentado pela empresa municipal responsável pela execução local da política (Cohab), no ano de 2011 foram entregues 1.162 unidades habitacionais; para 2012, a previsão de entrega é de 5.100 unidades; e as unidades remanescentes do programa, 1.168, têm previsão de entrega para 2013. Porém, de acordo com a mesma Cohab, atualmente há 45 mil famílias que aguardam encaminhamento para programas habitacionais, mostrando que, apenas nesse município, há déficit de 40 mil moradias.

\section{REFERÊNCIAS BIBLIOGRÁFICAS}

ABREU, João Maurício Martins de. A Moradia Informal no Banco dos Réus: discurso normativo e prática judicial. Revista de Direito FGV no 14. São Paulo, 2011, p. 391-415.

ALAPANIAN, Silvia. A Crítica Marxista do Direito: um olhar sobre as posições de EvgeniPachukanis. In: NAVES, Márcia Bilharinho. (org). O Discreto Charme do Direito Burguês. Campinas: UNICAMP, 2009, p. 21-42.

BIX, Brian. Robert Alexy, a Fórmula Radbruchiana, e a Natureza da Teoria do Direito. Revista Panóptica, no 12. 2008, p. 70-79 Disponível em:

http://www.panoptica.org/marjun08pdf/marjun08007.pdf. Acesso em 01 set. 2012.

BOBBIO, Norberto. Teoria da Norma Jurídica. Trad. Fernando Pavan Batista e Ariane Bueno Sudatti. Bauru: EDIPRO, 2008.

CANOTILHO, José Joaquim Gomes. Direito Constitucional e Teoria da Constituição. 4. ed., Coimbra: Almedina, 2000.

COMPARATO, Fábio Konder. A Afirmação Histórica dos Direitos Humanos. 7. ed., São Paulo: Editora Saraiva, 2010.

DIAS, Francisco Barros. O Significado das Expressões Eficácia e Efeito entre alguns Doutrinadores na Teoria Geral do Direito e no Campo Processual. Revista FIDES, vol. 1, nº 1, Natal, 2010, p. 18-21.

FRANCO, Alberto de Magalhães Filho. A Proto Historia dos Direitos Humanos Fundamentais. Revista Direitos Fundamentais e Democracia, vol. 7, Unibrasil: Curitiba, 2010, p. 188-208.

HESPANHA, Antônio Manuel. Categorias: Uma reflexão sobre a prática de classificar. Revista Análise Social. Vol. XXXVIII. Lisboa, 2003, p. 188-208. Disponível em:

http://analisesocial.ics.ul.pt/documentos/1218791402J5rXO3fg3Hg98TM7.pdf. Acesso em 17 jul. 2012.

HUBERMAN, Leo. A História da Riqueza do Homem. Rio de Janeiro: Zahar Editores, 1981. HÖFLING, Eloisa de Mattos. O Estado e Políticas (públicas) Sociais. Cadernos Cedes, ano XXI, n 55 , nov. 2001, p. 30-41.

KELSEN, Hans. Teoria Pura do Direito. Trad. João Baptista Machado. São Paulo: Martins Fontes, 2003.

\footnotetext{
${ }^{48}$ A Política pública nacional de habitação social foi instituída primeiramente por meio da Medida Provisória n 459, de 25 de março de 2009.
} 
LIMA, George Marmelstein. Efetivação do Direito Fundamental a Saúde pelo Poder Judiciário. Monografia final de curso. Faculdade de Direito da Universidade de Brasília: Brasília, 2003.

. Curso de Direitos Fundamentais. São Paulo: Editora Atlas, 2009.

MAILLART, Adriana da Silva; SANCHES, Samyra Dal Farra Naspolini. Os Limites à Liberdade na Autonomia Privada. Revista Pensar. Vol. 16. Fortaleza, 2011, p. 9-30. Disponível em http://ojs.unifor.br/index.php/rpen/article/view/2144. Acesso em 23 jul. 2012. MASTRODI, Josué. Direitos Sociais Fundamentais. Rio de Janeiro: Lumen Juris, 2008. . Sobre o Real Fundamento dos Direitos Fundamentais. Revista Digital de Direito Público, vol. 1, nº 1, 2012, p. 150-187.

MASCARO, Alysson Leandro. Pachukanis e Stuchka: o direito, entre o poder e o capital. In: NAVES, Márcia Bilharinho. (org). O Discreto Charme do Direito Burguês. Campinas: UNICAMP, 2009, p. 45-53.

Nos Extremos do Direito. Revista Lua Nova, n 57, São Paulo, 2002, p. 135-140.

NUNES, António José Avelãs. As Duas Últimas Máscaras do Estado Capitalista. Revista Pensar. Vol. 16, nº 2, Fortaleza, 2011, p. 409-476.

QUEIROZ, Cristina M. M. Direitos Fundamentais: Teoria Geral. 1. ed., Coimbra: Editora Coimbra, 2002.

ROLNIK, Raquel; KLINK, Jeroen. Crescimento Econômico e Desenvolvimento Urbano. Revista Novos Estudos. Março de 2011, p. 89-109. Disponível em:

http://mww.scielo.br/scielo.php?pid=S0101-33002011000100006\&script=sci_arttext. Acesso em 11 jul. 2012.

SARLET, Ingo Wolfgang. A Eficácia dos Direitos Fundamentais: uma teoria geral dos direitos fundamentais na perspectiva constitucional. 10. ed., rev. atual. e ampl. Porto Alegre: Editora Livraria do Advogado, 2009.

SPOSATI, Aldaiza. Tendências Latino-americanas da Política Social Pública no Século 21. Revista Katálysis, vol. 14, nº 1, Curitiba, 2011, p. 104-115.

WOLKMER, Antônio Carlos. Marx, a Questão Judaica e os Direitos Humanos. Revista Sequência, nº 48, jul. 2004, p. 11-28. 